Check for updates

Cite this: Chem. Sci., 2019, 10, 7812

๑ All publication charges for this article have been paid for by the Royal Society of Chemistry

Received 22nd February 2019

Accepted 22nd June 2019

DOI: $10.1039 /$ c9sc00926d

rsc.li/chemical-science

\section{Nucleophile-intercepted Beckmann fragmentation reactions $\uparrow$}

\author{
Samuel J. Touchette, Evan M. Dunkley, Leah L. Lowder and Jimmy Wu (DD*
}

We describe the first examples of nucleophile-intercepted Beckmann fragmentations of indoline oximes. This reaction uses $\mathrm{MsCl}$ as a promoter to give cyano chlorides and is believed to proceed through an aziridinium intermediate via a double stereoinvertive process. Mechanistic insights have led to the further discovery that oxygen, nitrogen, and bromide nucleophiles can be employed for this fragmentation by the use of other promoters. We envision that these products may be useful in the syntheses of members of the akuammiline and koumine families of indoline alkaloids.

\section{Introduction}

First reported in 1886, the classic Beckmann rearrangement converts ketoximes to the corresponding amides (Fig. 1). ${ }^{1}$ In the intervening time, numerous variants of this reaction have been reported and can be broadly classified into two categories: (1) trapping of the intermediate nitrilium ions and/or imidates with nucleophiles other than water, and (2) fragmentation to give nitriles. ${ }^{2}$ These fragmentation reactions nearly always involve Grob-like elimination processes to give an unsaturated component, such as an alkene or carbonyl, concomitant with scission of a $\mathrm{C}-\mathrm{C}$ bond. Furthermore, aldoximes routinely undergo direct $\mathrm{E} 2$ elimination at the oxime to give nitriles.

In contrast, Beckmann fragmentation reactions of ketoximes that circumvent the elimination step, and instead proceed by

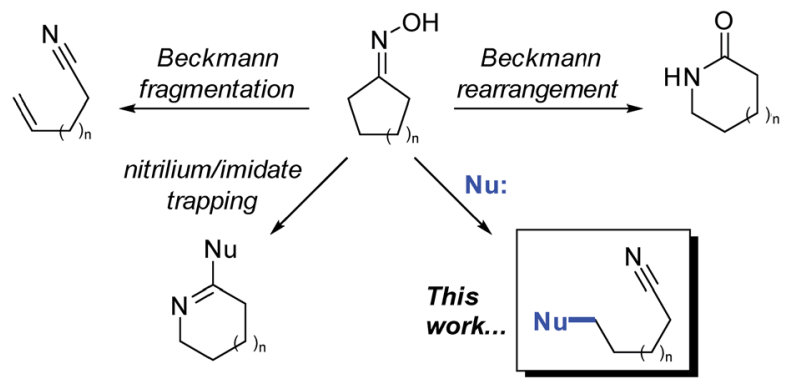

Fig. 1 Major classes of variations on the Beckmann rearrangement.

Department of Chemistry, Dartmouth College, Hanover, New Hampshire 03755, USA. E-mail: jimmy.wu@dartmouth.edu

$\uparrow$ Electronic supplementary information (ESI) available: Experimental details and characterization of all new compounds, selected 2D-NOESY, COSY, HMBC, HSQC data, and X-ray data for 4a and 5a. CCDC 1898982 and 1898983. For ESI and crystallographic data in CIF or other electronic format see DOI: 10.1039/c9sc00926d nucleophilic attack, are exceedingly rare (Fig. 1; this work). The few reported instances of nucleophile-intercepted Beckmann fragmentations are typically minor components of undesired side-reactions and constrained to highly specialized substrates..$^{3-9}$ Despite the scarcity of precedents, we envisioned that a broadly general variant of such a transformation could potentially serve as a powerful tool in the preparation of densely-functionalized indoline systems. Herein, we report the first instance of nucleophile-intercepted Beckmann fragmentations of indolinyl oximes using a diverse set of nucleophiles to generate cyclohexa $[b]$ indolines featuring four contiguous stereocenters (eqn (1)). We anticipate that rapid and efficient access to these compounds may be useful in the synthesis of members of the akuammiline $\mathrm{e}^{10-12}$ and koumine $\mathrm{13-16}^{13}$ families of natural products (Fig. 2). These are important classes of bioactive indoline alkaloids of which there are several dozen members. ${ }^{17-20}$

Our research group has been interested in the development of novel reactions involving indoles and related heterocycles for
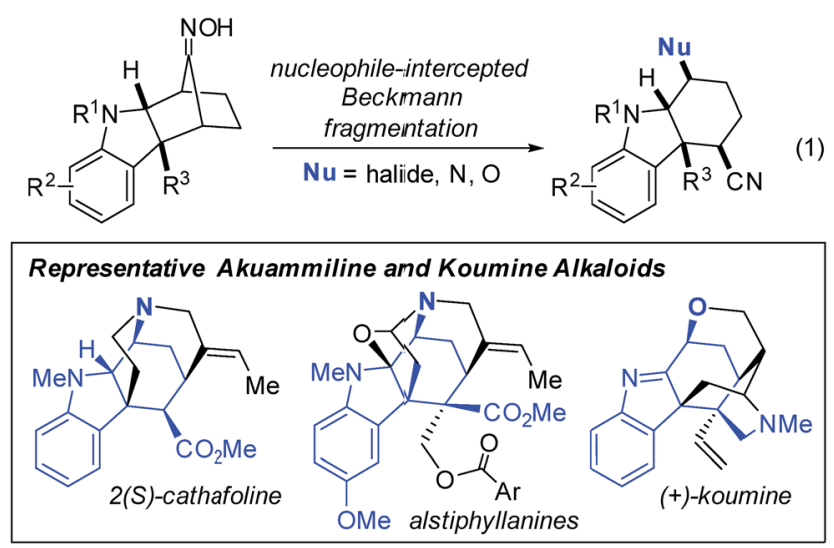

Fig. 2 Nucleophile-intercepted Beckmann fragmentation reactions of indolinyl oximes and representative members of the akuammiline and koumine alkaloids. 


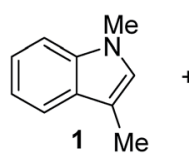<smiles>O=C1CCCC1Cl</smiles>
$\underset{\mathrm{TFE}}{\stackrel{\mathrm{Na}_{2} \mathrm{CO}_{3}}{\longrightarrow}}$

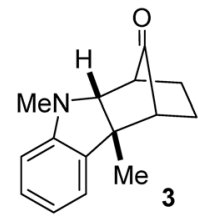

1. $\mathrm{NH}_{2} \mathrm{OH} \cdot \mathrm{HCl}$

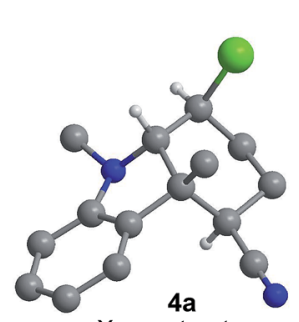

$\mathrm{X}$-ray structure

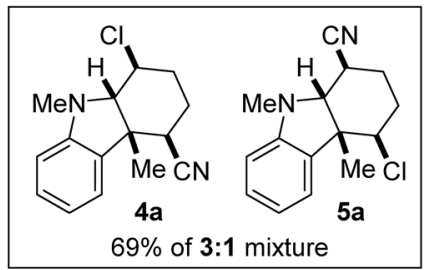

Scheme 1 Discovery of the nucleophile-intercepted Beckmann fragmentation.

some time..$^{21-28}$ In this context, we have previously reported the $(3+2)$ annulation between 3 -substituted indoles and various oxyallyl cations generated from $\alpha$-haloketones to give bicycloketone 3 (Scheme 1). ${ }^{23}$ In the following work, we converted 3 to the corresponding oxime with $\mathrm{NH}_{2} \mathrm{OH} \cdot \mathrm{HCl}$. Upon treatment with $\mathrm{MsCl}$, none of the bicyclic lactam regioisomers resulting from prototypical Beckmann rearrangement was obtained. Instead, we were surprised to isolate cyano chloride $4 \mathrm{a}$ in $52 \%$ yield along with $17 \%$ of its regioisomer $\mathbf{5 a}$, both of whose gross structures and relative stereochemical relationships were assigned based on X-ray crystallography and extensive NMR spectroscopy. No epimeric compounds were observed.

Intrigued by this unexpected finding, we wondered whether the transformation was more broadly general. Indeed, the nucleophile-intercepted Beckmann fragmentation was compatible with a wide range of substituents at $R^{1}-R^{3}$ and functional groups (Table 1). The indoline nitrogen may be functionalized with methyl, benzyl, and TBS (entries 1-4); although for the silylated substrate, the product was isolated as the desilylated $\mathrm{N}-\mathrm{H}$ compound (entry 4). Furthermore, the aromatic nucleus of the indoline may be substituted with various halides, methyl, or the electron-rich methoxy group (entries 2, 6-10 and 12). Reactions involving both tryptamineand tryptophol-derived oximes $\mathbf{6 k - \mathbf { o }}$ also proceeded smoothly to provide the desired products (entries 11-15). The use of oximes with a free $\mathrm{N}-\mathrm{H}$ indoline nitrogen resulted in decomposition. The range of regioselectivity between 4 of 5 was broad and varied from $3: 1$ to greater than $95: 5$. In nearly all instances, the regioisomers were separable by silica gel flash chromatography. We did not detect any Grob-like fragmentation products in any of the reactions.

Based on what is known about the Beckmann rearrangement and the stereochemical outcome of the product, ${ }^{29}$ we propose the mechanism depicted in Scheme 2. It is known that the functionalization of compounds containing carbon-nitrogen double bonds with electron-withdrawing groups at nitrogen facilitates its interconversion between $E$ and $Z$ isomers. ${ }^{30} \mathrm{We}$ therefore hypothesize that the equilibration between mesylates
Table 1 Scope of the nucleophile-intercepted Beckmann fragmentation $^{a}$

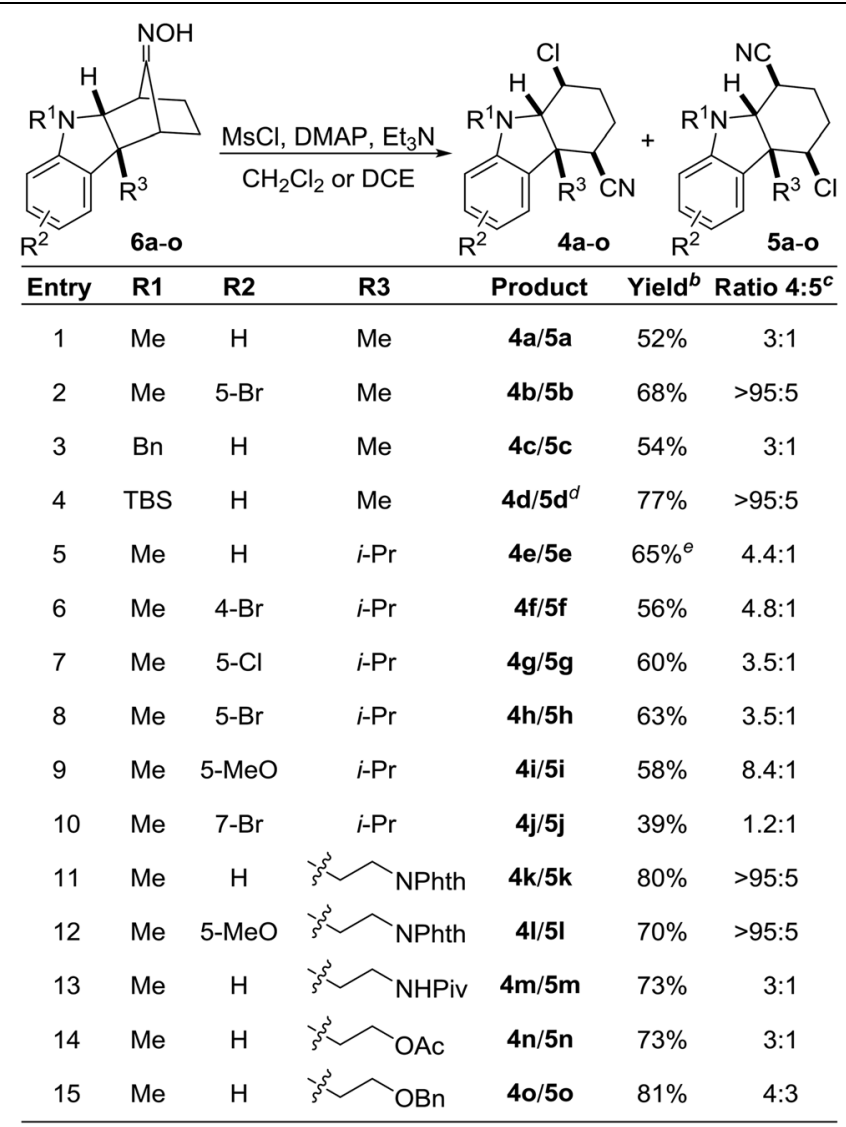

${ }^{a}$ Reaction conditions: 6 ( 1 equiv.), MsCl (3 equiv.), DMAP (5 mol\%), $\mathrm{Et}_{3} \mathrm{~N}$ (5 equiv.), [0.2] M. ${ }^{b}$ Isolated yield of only the major isomer 4. ${ }^{c}$ As determined by ${ }^{1} \mathrm{H}$ NMR spectroscopy of unpurified residue. ${ }^{d}$ Isolated as $\mathrm{R}^{1}=\mathrm{H} .{ }^{e}$ Isolated as a $2.5: 1$ mixture of $4 \mathrm{e} / 5 \mathrm{e}$.

$(E)-7$ and $(Z)-7$ is rapid and propose that the ensuing fragmentation is both rate-limiting and irreversible. This may proceed via a stereospecific process enabled in part by neighboring group participation of the non-bonding electrons of the indoline nitrogen to give aziridinium intermediate 8 with inversion of configuration. There is little steric bias between $(E)-7$ and $(Z)$ 7. However, due to the stereoelectronic requirement of the mesylate leaving group to be anti to the migrating carbon, we believe that the geometry of the oxime mesylate is the primary determinant of the regiochemical outcome of the reaction. Thus, this sets up a classic Curtin-Hammett scenario in which the product distribution is governed by the relative difference in the transition state energies $\left(\Delta \Delta G^{\ddagger}\right)$ of $(E)-7 \rightarrow \mathbf{8}$ versus $(Z)-7 \rightarrow$ 9. This proposal is supported, in part, by the observation that the product distribution between $\mathbf{4}$ and $\mathbf{5}$ is consistently greater than that of the $E / Z$ diastereomeric ratio of the corresponding oxime starting materials (typically $1: 1 \mathrm{dr}$ ). Subsequent attack of aziridinium 8 by chloride also occurs with inversion to give the major product $4 \mathbf{a}$ with the stereochemical outcome shown. Formation of the minor regioisomeric product 5a may occur analogously through phenonium intermediate $\mathbf{9}$. 


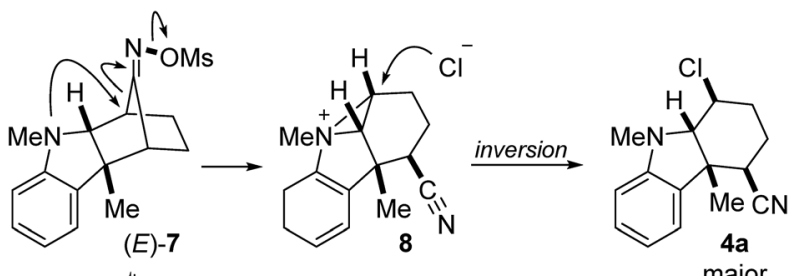

$(E)-7$

major
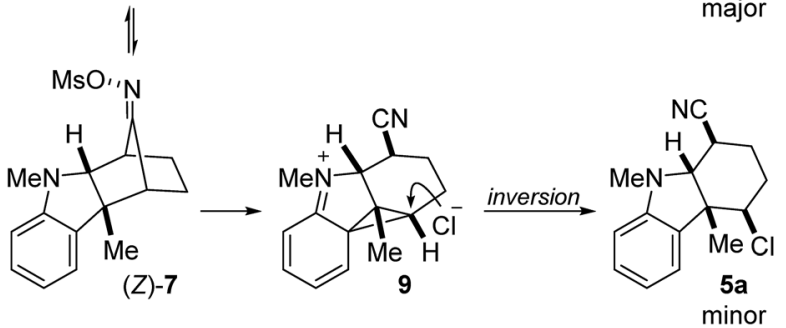

Scheme 2 Proposed mechanism of the nucleophile-intercepted Beckmann rearrangement.

Guided by these mechanistic insights, we next sought to expand the scope of the nucleophile-intercepted Beckmann fragmentation to include nucleophiles besides chloride. We reasoned that the use of promoters other than $\mathrm{MsCl}$ would activate the oxime for fragmentation yet provide different nucleophiles for opening the putative intermediates 8 and $\mathbf{9}$. Table 2 summarizes these results. Thus, treating various oximes 6 with diphenylphosphoryl azide (DPPA) resulted in the formation of the expected cyano azides (entries 1, 6 and 7). Surprisingly, relatively weak nucleophiles generated by promoters such as $\mathrm{PhNTf}_{2}$, TFAA, and $\mathrm{Ms}_{2} \mathrm{O}$ were also effective in giving the corresponding triflamide, trifluoroacetate, and

Table 2 Scope of the promoter $^{a}$

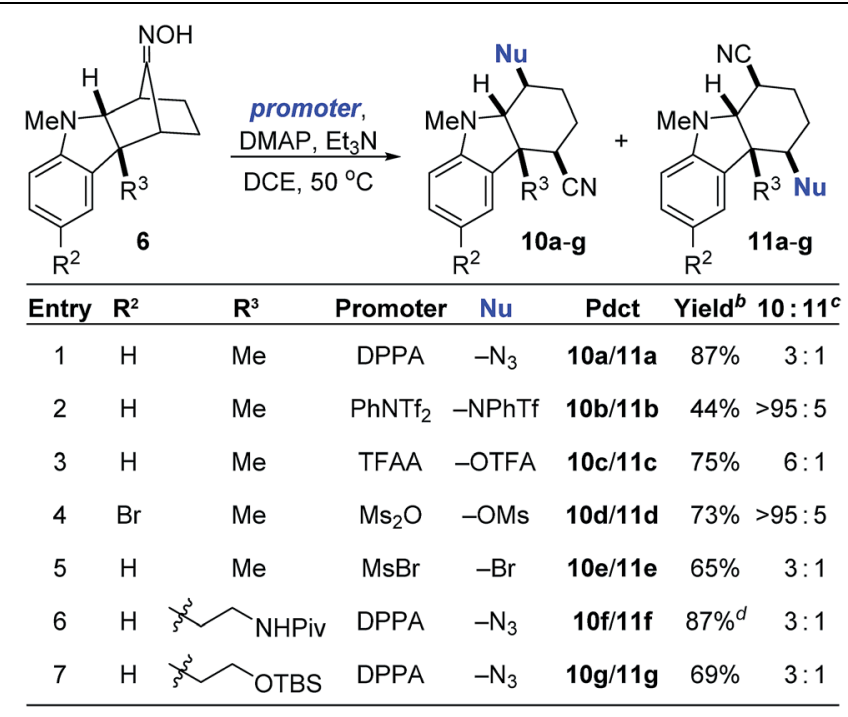

${ }^{a}$ Reaction conditions: 6 (1 equiv.), promoter (3 equiv.), DMAP (5 mol\%), $\mathrm{Et}_{3} \mathrm{~N}$ (5 equiv.), [0.2] M. ${ }^{b}$ Isolated yield of only the major isomer $10 .{ }^{c} \mathrm{As}$ determined by ${ }^{1} \mathrm{H}$ NMR spectroscopy of the unpurified residue. ${ }^{d}$ Isolated as a $3: 1$ mixture of 10f/11f. DPPA = diphenylphosphoryl azide; TFAA $=$ trifluoroacetic anhydride; OTFA $=$ trifluoroacetate.
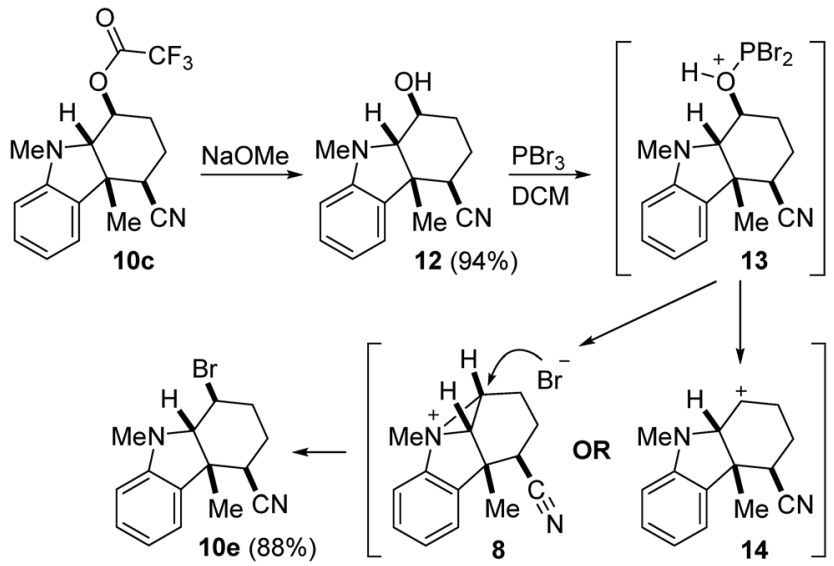

Scheme 3 Preliminary data in support of aziridinium 8

mesylate products (entries 2-4). Bromides can be obtained when using $\mathrm{MsBr}$ (entry 5). The use of $\mathrm{Tf}_{2} \mathrm{NBz}$ resulted in benzoylation of the oxime oxygen without further reaction (see ESI $\dagger$ ). As was also the case in Table 1, the ratio of major to minor products fluctuates greatly in response to subtle changes in substrate structure. We do not yet fully understand the factors that dictate these product distributions.

To test the validity of the proposed aziridinium intermediate 8, we elected to study the stereochemical outcome of the conversion of 10c and 12 to the corresponding bromide (Scheme 3). Our working hypothesis was that the activation of alcohol 12 may lead to the regeneration of the putative aziridinium intermediate $\mathbf{8}$, which may then be opened by bromide. This process would proceed by double stereoinversion to give 10e with the stereochemical relationship shown. However, if the reaction were to progress through the free carbocation 14, then we might reasonably expect to observe the formation of diastereomeric or alkene by-products. Thus, trifluoroacetate 10c was hydrolyzed to 12 (94\% yield) and then treated with $\mathrm{PBr}_{3}$ to furnish 10e ( $88 \%$ yield) as the only observable product. That we did not detect the presence of either olefinic or stereoisomeric compounds is consistent with the intermediacy of aziridinium $\mathbf{8}$, although stereoselective trapping of $\mathbf{1 4}$ by the nucleophile cannot be definitively ruled out.

\section{Conclusions}

In summary, we have reported the first instance of a general nucleophile-intercepted Beckmann rearrangements of indolinyl oximes. The reaction is amenable to a wide range of functional groups on the starting material. Furthermore, various promoters can be utilized to introduce oxygen, nitrogen, and halide substituents into the final products. The available evidence supports a stereospecific fragmentation of the activated oxime to give an aziridinium intermediate as the likely rate-limiting step. We believe that this reaction may be useful in future synthetic endeavors towards indoline alkaloids such as the akuammiline family and koumine-type of natural products. Efforts are ongoing in our laboratories towards these targets. 


\section{Conflicts of interest}

There are no conflicts to declare.

\section{Acknowledgements}

J. W. acknowledges the generous support of the NIH NIGMS (R01GM111638).

\section{Notes and references}

1 E. Beckmann, Ber. Dtsch. Chem. Ges., 1886, 19, 988-993.

2 R. E. Gawley, in Organic Reactions, ed. A. S. Kende, John Wiley \& Sons, Inc., 1988, vol. 35.

3 A. Hassner and E. G. Nash, Tetrahedron Lett., 1965, 6, 525529.

4 K. Hirao, H. Miura and O. Yonemitsu, Heterocycles, 1977, 7, 857.

5 P. N. Confalone, G. Pizzolato, D. Lollar-Confalone and M. R. Uskokovic, J. Am. Chem. Soc., 1980, 102, 1954-1960.

6 R. J. Hunadi and G. K. Helmkamp, J. Org. Chem., 1981, 46, 2880-2884.

7 M. Kirihara, K. Niimi, M. Okumura and T. Momose, Chem. Pharm. Bull., 2000, 48, 220-222.

8 W. Ai, Y. Liu, Q. Wang, Z. Lu and Q. Liu, Org. Lett., 2018, 20, 409-412.

9 E. M. Dauncey, S. P. Morcillo, J. J. Douglas, N. S. Sheikh and D. Leonori, Angew. Chem., Int. Ed., 2018, 57, 744-748.

10 A. Ramirez and S. García-Rubio, Curr. Med. Chem., 2003, 10, 1891-1915.

11 R. Eckermann and T. Gaich, Synthesis, 2013, 45, 2813-2823.

12 J. M. Smith, J. Moreno, B. W. Boal and N. K. Garg, Angew. Chem., Int. Ed., 2015, 54, 400-412.

13 P. Magnus, B. Mugrage, M. DeLuca and G. A. Cain, J. Am. Chem. Soc., 1989, 111, 786-789.

14 P. Magnus, B. Mugrage, M. R. DeLuca and G. A. Cain, J. Am. Chem. Soc., 1990, 112, 5220-5230.

15 Y.-K. Xu, L. Yang, S.-G. Liao, P. Cao, B. Wu, H.-B. Hu, J. Guo and P. Zhang, J. Nat. Prod., 2015, 78, 1511-1517.

16 J. K. Kerkovius and M. A. Kerr, J. Am. Chem. Soc., 2018, 140, 8415-8419.

17 H. Arai, Y. Hirasawa, A. Rahman, I. Kusumawati, N. C. Zaini, S. Sato, C. Aoyama, J. Takeo and H. Morita, Bioorg. Med. Chem., 2010, 18, 2152-2158.

18 Y. Xu, H.-Q. Qiu, H. Liu, M. Liu, Z.-Y. Huang, J. Yang, Y.-P. Su and C.-X. Yu, Pharmacol., Biochem. Behav., 2012, 101, 504514.
19 B.-J. Xiong, Y. Xu, G.-L. Jin, M. Liu, J. Yang and C.-X. Yu, Sci. Rep., 2017, 7, 14269.

20 S. E. Kearney, G. Zahoránszky-Kőhalmi, K. R. Brimacombe, M. J. Henderson, C. Lynch, T. Zhao, K. K. Wan, Z. Itkin, C. Dillon, M. Shen, D. M. Cheff, T. D. Lee, D. Bougie, K. Cheng, N. P. Coussens, D. Dorjsuren, R. T. Eastman, R. Huang, M. J. Iannotti, S. Karavadhi, C. Klumpp-Thomas, J. S. Roth, S. Sakamuru, W. Sun, S. A. Titus, A. Yasgar, Y.-Q. Zhang, J. Zhao, R. B. Andrade, M. K. Brown, N. Z. Burns, J. K. Cha, E. E. Mevers, J. Clardy, J. A. Clement, P. A. Crooks, G. D. Cuny, J. Ganor, J. Moreno, L. A. Morrill, E. Picazo, R. B. Susick, N. K. Garg, B. C. Goess, R. B. Grossman, C. C. Hughes, J. N. Johnston, M. M. Joullie, A. D. Kinghorn, D. G. I. Kingston, M. J. Krische, O. Kwon, T. J. Maimone, S. Majumdar, K. N. Maloney, E. Mohamed, B. T. Murphy, P. Nagorny, D. E. Olson, L. E. Overman, L. E. Brown, J. K. Snyder, J. A. Porco, F. Rivas, S. A. Ross, R. Sarpong, I. Sharma, J. T. Shaw, Z. Xu, B. Shen, W. Shi, C. R. J. Stephenson, A. L. Verano, D. S. Tan, Y. Tang, R. E. Taylor, R. J. Thomson, D. A. Vosburg, J. Wu, W. M. Wuest, A. Zakarian, Y. Zhang, T. Ren, Z. Zuo, J. Inglese, S. Michael, A. Simeonov, W. Zheng, P. Shinn, A. Jadhav, M. B. Boxer, M. D. Hall, M. Xia, R. Guha and J. M. Rohde, ACS Cent. Sci., 2018, 4, 1727-1741.

21 X. Han, H. Li, R. P. Hughes and J. Wu, Angew. Chem., Int. Ed., 2012, 51, 10390-10393.

22 X. Han and J. Wu, Angew. Chem., Int. Ed., 2013, 52, 46374640.

23 H. Li, R. P. Hughes and J. Wu, J. Am. Chem. Soc., 2014, 136, 6288-6296.

24 M. C. DiPoto, R. P. Hughes and J. Wu, J. Am. Chem. Soc., 2015, 137, 14861-14864.

25 O. G. Chepurny, C. A. Leech, M. Tomanik, M. C. DiPoto, H. Li, X. Han, Q. Meng, R. N. Cooney, J. Wu and G. G. Holz, Sci. Rep., 2016, 6, 28934.

26 J. Chen and J. Wu, Angew. Chem., Int. Ed., 2017, 56, 39513955.

27 M. C. DiPoto and J. Wu, Org. Lett., 2018, 20, 499-501.

28 J. Chen and J. Wu, Chem. Sci., 2018, 9, 2489-2492.

29 S. Yamabe, N. Tsuchida and S. Yamazaki, J. Org. Chem., 2005, 70, 10638-10644.

30 J. Gálvez and A. Guirado, J. Comput. Chem., 2009, 520-531. 